\title{
Commercial Biocides Induce Transfer of Prophage $\Phi 13$ from Human Strains of Staphylococcus aureus to Livestock CC398
}

\begin{abstract}
Yuanyue Tang ${ }^{1}$, Lene N. Nielsen ${ }^{2}$, Annemette Hvitved ${ }^{2}$, Jakob K. Haaber ${ }^{3}$, Christiane Wirtz ${ }^{4}$, Paal S. Andersen ${ }^{1,5}$, Jesper Larsen ${ }^{5}$, Christiane Wolz ${ }^{4}$ and Hanne Ingmer ${ }^{\text {1* }}$
\end{abstract}

\begin{abstract}
${ }^{1}$ Department of Veterinary and Animal Science, Faculty of Health and Medical Sciences, University of Copenhagen, Frederiksberg, Denmark, ${ }^{2}$ National Food Institute, Technical University of Denmark, Søborg, Denmark, ${ }^{3}$ DTU Biosustain, Technical University of Denmark, Kongens Lyngby, Denmark, ${ }^{4}$ Institut für Medizinische Mikrobiologie und Hygiene, Universitätsklinikum Tübingen, Tübingen, Germany, ${ }^{5}$ Department of Microbiology and Infection Control, Statens Serum Institut, Copenhagen, Denmark
\end{abstract}

Human strains of Staphylococcus aureus commonly carry the bacteriophage $\Phi$ Sa3 that encodes immune evasion factors. Recently, this prophage has been found in

OPEN ACCESS

Edited by:

Peter Mullany,

University College London,

United Kingdom

Reviewed by:

Chad W. Euler,

Hunter College (CUNY), United States

Grzegorz Wegrzyn,

University of Gdańsk, Poland

${ }^{*}$ Correspondence: Hanne Ingmer hi@sund.ku.dk

Specialty section: This article was submitted to Antimicrobials, Resistance and Chemotherapy,

a section of the journal

Frontiers in Microbiology

Received: 28 September 2017 Accepted: 22 November 2017 Published: 07 December 2017

Citation:

Tang Y, Nielsen LN, Hvitved A, Haaber JK, Wirtz C, Andersen PS, Larsen J, Wolz C and Ingmer H (2017) Commercial Biocides Induce Transfer of Prophage $\Phi 13$ from Human Strains of Staphylococcus aureus to Livestock CC398. Front. Microbiol. 8:2418. doi: 10.3389/fmicb.2017.02418 livestock-associated, methicillin resistant S. aureus (MRSA) CC398 strains where it may promote human colonization. Here, we have addressed if exposure to biocidal products induces phage transfer, and find that during co-culture, $\Phi 13$ from strain 8325, belonging to $\Phi$ Sa3 group, is induced and transferred from a human strain to LA-MRSA CC398 when exposed to sub-lethal concentrations of commercial biocides containing hydrogen peroxide. Integration of $\Phi$ Sa3 in LA-MRSA CC398 occurs at multiple positions and the integration site influences the stability of the prophage. We did not observe integration in $h / b$ encoding $\beta$-hemolysin that contains the preferred $\Phi S \mathrm{Sa}$ attachment site in human strains, and we demonstrate that this is due to allelic variation in CC398 strains that disrupts the phage attachment site, but not the expression of $\beta$-hemolysin. Our results show that hydrogen peroxide present in biocidal products stimulate transfer of $\Phi$ Sa3 from human to LA-MRSA CC398 strains and that in these strains prophage stability depends on the integration site. Knowledge of $\Phi \mathrm{Sa} 3$ transfer and stability between human and livestock strains may lead to new intervention measures directed at reducing human infection by LA-MRSA strains.

Keywords: LA-MRSA CC398, biocide, prophage, $\Phi$ Sa3, phage transfer

\section{INTRODUCTION}

Staphylococcus aureus is an opportunistic pathogen in human and animals, and is one of the leading causes of acute and chronic infections. When treating staphylococcal infections, resistance to $\beta$ lactam antibiotics is an increasing problem with methicillin resistant $S$. aureus (MRSA) clones epidemically spreading in the hospitals as well as in the community (DeLeo et al., 2010; Dulon et al., 2011). In recent years, strains belonging to clonal complex 398 (CC398) have been widely detected in pigs and have also been found in other livestock animals such as turkey, chicken and cattle (Smith and Pearson, 2011). In general, livestock-associated MRSA (LA-MRSA) CC398 is regarded 
less virulent than human-associated MRSA clones due to the absence of several common virulence factors, such as enterotoxins and phage encoded Panton-Valentine leukocidin (PVL) (Schijffelen et al., 2010; Price et al., 2012; Becker et al., 2015). However, LA-MRSA CC398 causes infections in humans with livestock contact (Köck et al., 2011; Pérez-Moreno et al., 2016) and since first detected in the early 2000s (van Loo et al., 2007) the number of clinical cases in humans has increased steadily (van Cleef et al., 2011; Cuny et al., 2015). The infection of humans by LA-MRSA CC398 is primarily regarded as an occupational risk for farmers, veterinarians and meat handlers (Smith and Pearson, 2011) but a secondary risk is the spread of CC398 to the community (Smith and Pearson, 2011; Smith, 2015). In fact, infections of LA-MRSA CC398 in patients without animal contact have been reported both in Europe and the United States (Welinder-Olsson et al., 2008; Wulf et al., 2008; Bhat et al., 2009; Larsen et al., 2015, 2016; Diene et al., 2017).

The ability of $S$. aureus to colonize host organisms is in part determined by prophages. The majority of humanassociated $S$. aureus isolates contain $\beta$-hemolysin negativeconverting bacteriophages, which are classified as $\Phi$ Sa3 (Goerke et al. 2006b). They share an integrase (Goerke et al., 2009) and an attachment core sequence (5'-TGTATCCAAACTGG-3') in the hlb gene (Coleman et al., 1991). $\Phi$ Sa3 phages contain the immune evasion cluster (IEC) encoding the chemotaxin inhibitory protein (CHIPS), staphylococcal complement inhibitor (SCIN), staphylokinase (SAK), as well as some enterotoxins (Coleman et al., 1989; van Wamel et al., 2006; Goerke et al., 2009; McCarthy and Lindsay, 2010), which contribute to adaptation to the human host (de Haas et al., 2004; Rooijakkers et al., 2005; Jung et al., 2016). Recent data suggest that $\Phi$ Sa3 phages are occasionally found in livestock-associated $S$. aureus strains, and the acquisition of $\Phi S a 3$ is important for the host-jump of S. aureus from animals to humans (Price et al., 2012; van der Mee-Marquet et al., 2014; Larsen et al., 2015, 2016).

Induction of prophages generally occurs in response to DNA damage elicited by for example reactive oxygen species and some antibiotics, and is mediated by RecA activation and cleavage of the phage repressor (Frye et al., 2005; Goerke et al., 2006a; Nanda et al., 2015). Thus, extrinsic factors contribute to the mobility of $\Phi S a 3$ phages among $S$. aureus strains. Disinfection and cleaning are critical steps when maintaining a desired hygiene status in household products, in hospitals and in food animal production. In livestock production, biocides are widely applied for cleaning and disinfection of animalassociated production areas, equipment, during transport and even directly on animals to prevent skin diseases (Quinn and Markey, 2001). Major biocides applied in livestock production include hydrogen peroxide, peracetic acid, glutaric aldehyde, quaternary ammonium compounds, and isopropanol (Kjølholt et al., 2001; SCHENIHR (Scientific Committee on Emerging and Newly Identified Health Risks), 2009). Hydrogen peroxide is a common disinfectant applied in animal production. It is a powerful oxidizing agent that oxidizes thiol groups in enzymes and proteins and leads to free radical production (Kjølholt et al., 2001; Russell, 2003). Here we have applied a prophage $\Phi 13$ from strain 8325 belonging to $\Phi$ Sa3 group to examine if sub-lethal concentrations of commercial biocides and biocidal compounds induce phage $\Phi \mathrm{Sa} 3$ and stimulate its transmission to LA-MRSA CC398 strains.

\section{MATERIALS AND METHODS}

\section{Strain Collection and Chemical Reagents}

Chemicals and biocides used in this study are listed in Table 1 and strains in Table 2. Media used in this study included MuellerHinton broth (MHB), tryptic soy broth (TSB) and agar (TSA) from Oxoid. Sheep blood is from Department of Veterinary Disease Biology, University of Copenhagen.

\section{Strain Construction}

Phage-cured MW2c was obtained by treating MW2- $\Phi$ Sa3mw (Wirtz et al., 2009) with $1 \mu \mathrm{g} / \mathrm{ml}$ mitomycin $\mathrm{C}$ for $2 \mathrm{~h}$ at $37^{\circ} \mathrm{C}, 200$ rpm in TSB and subsequently with $0.5 \mathrm{mM}$ hydrogen peroxide for $3 \mathrm{~h}$ at $37^{\circ} \mathrm{C}, 200 \mathrm{rpm}$. Serial dilutions were plated on TSA with $0.5 \mathrm{mM}$ hydrogen peroxide and incubated at $37^{\circ} \mathrm{C}$ for overnight. Colonies grew on the plates were selected as phage cured bacteria (MW2c) and checked by PFGE (Goerke et al., 2004) for lacking of the phage.

Strain 8325-4Ф13-kana was obtained by replacing part of the $3^{\prime}$-end of $\Phi 13$ (chps and scin) in strain $\Phi 8325-4 \Phi 13$ (Goerke et al., 2006a) with kanamycin resistance cassette aphA3. In brief, two fragments flanking the $3^{\prime}$-region of $\Phi 13$ and the kanamycinresistant cassette from pDG782 (Guérout-Fleury et al., 1995) were amplified and annealed by overlapping PCR. The amplicon was cloned into KpnI restriction site into pBT2 (Brückner, 2006) to gain pCG6, which was electroporated into strain RN4220

TABLE 1 | Biocides and chemical regents included in this study.

\begin{tabular}{lll}
\hline Regents & Composition & Manufacturer \\
\hline Biocide ${ }^{*}$ & Hydrogen peroxide (15-30\%) & Novadan \\
& $\begin{array}{l}\text { Acetic acid (5-15\%) } \\
\text { Peracetic acid (1-5\%) }\end{array}$ & \\
Biocide 2* & Hydrogen peroxide (15-30\%) & Novadan \\
& Acetic acid (1-5\%) & \\
& Peracetic acid (1-5\%) & \\
Biocide 3* & Phosphonic acid (1-5\%) & Novadan \\
& Amine oxide (1-5\%) & \\
Mitomycin C & Active chlorine (60-100\%) & Sigma-Aldrich \\
Hydrogen peroxide & Sodium hydroxide (1-5\%) & \\
Benzalkonium chloride & Amine oxide (<1\%) & Sigma-Aldrich \\
Acetic acid & Mitomycin C from Streptomyces & Sigma-Aldrich \\
Amine oxide & Acetic acid (100\%) & Merck \\
Peracetic acid & N,N-Dimethyldodecylamine N-oxide & Sigma-Aldrich \\
\hline (30\%) & Peracetic acid (38-40\%) & Merck \\
\hline
\end{tabular}

${ }^{*}$ Represents commercial biocide. 
TABLE 2 | Bacteria strains included in this study.

\begin{tabular}{|c|c|c|}
\hline Strain & Description & References \\
\hline $8325-4$ & NCTC8325 phage-cured & Novick, 1967 \\
\hline 8325-4Ф13 (CG1) & 8325-4 lysogenized with $\Phi 13$ & $\begin{array}{l}\text { Goerke et al., } \\
2006 a\end{array}$ \\
\hline RN4220 & $\begin{array}{l}\text { Restriction defective derivative of } \\
8325-4\end{array}$ & $\begin{array}{l}\text { Kreiswirth et al., } \\
1983\end{array}$ \\
\hline 8325-4Ф13-kana & $\begin{array}{l}8325-4 \text { lysogenized with } \Phi 13 \text { chips, } \\
\text { scin::aphA3, kanamycin resistant }\end{array}$ & This study \\
\hline MW2- $\Phi$ Sa3mw & MW2- $\Phi$ Sa3mw & Wirtz et al., 2009 \\
\hline MW2c & MW2 phage-cured & This study \\
\hline 61599 & $\begin{array}{l}\text { spa type t034, tetracycline resistant, } \\
\mathrm{hlb}^{+}\end{array}$ & Larsen et al., 2015 \\
\hline 93616 & $\begin{array}{l}\text { spa type t899, tetracycline resistant, } \\
\mathrm{hlb}^{+}\end{array}$ & Larsen et al., 2016 \\
\hline DC10B & $\begin{array}{l}\Delta d c m \text { in } \mathrm{DH} 10 \mathrm{~B} \text { background; Dam } \\
\text { methylation only }\end{array}$ & Monk et al., 2012 \\
\hline 8325-4Ф13attBmut & $\begin{array}{l}8325-4 \text { mutated at } \Phi 13 \text { attB site in } \\
h / b, h / b^{+}\end{array}$ & This study \\
\hline RN4220Ф13attBmut & $\begin{array}{l}\text { RN4220 mutated at } \Phi 13 \text { attB site in } \\
h / b, h / b^{+}\end{array}$ & This study \\
\hline
\end{tabular}

(Kreiswirth et al., 1983) and further transduced into 8325$4 \Phi 13$. pCG6 was then used to mutagenize strain $8325-4 \Phi 13$ as described by Brückner (2006) to obtain strain 8325-4Ф13kana, and confirmed by sequencing.

To identify the $\Phi 13$ attB site in strain 8325-4 (Novick, 1967) and RN4220 (Peng et al., 1988), the original $\Phi 13$ attB site in $8325-4$ was predicted by subtracting the $\Phi 13$ sequence (accession No.: NC_004617) from the NCTC 8325 genome harboring $\Phi 13$ (accession No.: NC_007795), and aligning the resulting sequence to the known $h l b$ sequence containing the $\Phi 13$ attB site (Coleman et al., 1991) (accession No.: X61716) for confirmation. To construct a plasmid containing a mutated $\Phi 13$ attB (attBmut), 800 bp upstream sequence of $\Phi 13$ attB site in $h l b$ gene of $8325-4$ (Novick, 1967) was amplified by overlapping PCR primer pairs pIMAYhlbattfor and hlbattmutrev (Supplementary Table 1), and 800 bp sequence downstream of $\Phi 13$ attB site was amplified by overlapping PCR primer pairs hlbattmutfor and pIMAYhlbattrev, where the $\Phi 13$ att B mutation from strain 61599 was included in primer hlbattmutfor (Supplementary Table 1). The PCR fragments and pIMAY vector were digested by EcoRI, and ligated together by Gibson Assembly ${ }^{\circledR}$ Master Mixt (BioLabs ${ }^{\circledR}$ ) to form the plasmid named as pIMAY_ $\Phi 13$ attmut. This plasmid was electroporated into RN4220 (Kreiswirth et al., 1983) resulting in the strain RN4220pIMAY_ $\Phi 13$ attmut, and the $\Phi 13$ attB mutation was introduced into the RN4220 chromosome by homologous recombination (Monk et al., 2012). The mutation at attB in RN4220 was confirmed by sequencing and the strain was named RN4220Ф13attBmut.

For construction of $\Phi 13$ attB mutation in strain 83254, plasmid pIMAY_ $\Phi 13$ attmut was electroporated from RN4220pIMAY_Ф13attmut into 8325-4 (Novick, 1967), and the $\Phi 13$ attB mutation from strain 61599 was introduced to $8325-4$ chromosome by homologous recombination with PIMAY allelic replacement system (Monk et al., 2012). The mutation at att $\mathrm{B}$ in $8325-4$ was confirmed by sequencing and the strain was named as $8325-4 \Phi 13$ attBmut.

\section{Determination of Minimal Inhibitory Concentrations (MICs)}

MICs of biocides and chemical compounds in strain 8325 $4 \Phi 13$ were determined according to the guideline of Clinical and laboratory standards institute (Clinical and Laboratory Standards Institute (CLSI), 2008). Strains from overnight TSA plate was resuspended in $0.9 \% \mathrm{NaCl}$ to achieve the turbidity of $0.5 \mathrm{McFarland}$ standard and further diluted 100-fold in MHB. The working solution of biocides and chemical compound were benzalkonium chloride $(2.67 \mu \mathrm{g} / \mathrm{ml})$, hydrogen peroxide $(3 \%$ w/w), Biocide 1 ( $5 \% \mathrm{v} / \mathrm{v})$, Biocide 2 (5\% v/v), Biocide $3(5 \% \mathrm{v} / \mathrm{v})$, and mitomycin $\mathrm{C}(1 \mu \mathrm{g} / \mathrm{ml})$. In brief, the working solution of biocides and mitomycin $\mathrm{C}$ were prepared with two-fold dilution series in MHB in 96-well microtiter plates with $100 \mu \mathrm{l}$ volume. Further, $100 \mu \mathrm{l}$ of cell suspension was added to each well. Positive growth control of wells without biocide, and negative controls of wells with only $\mathrm{MHB}$ were included. The microtiter plates were incubated at $37^{\circ} \mathrm{C}$ for $24 \mathrm{~h}$. MIC values were determined as the lowest concentration of the compounds that eliminated the visible growth of bacteria.

\section{$\Phi 13$ Induction Assay by Different Biocides and Mitomycin C}

To perform the phage induction assay, strain $8325-4 \Phi 13$ was grown to the exponential phase $\left(\mathrm{OD}_{600}=0.8\right)$ (Wirtz et al., 2009) by shaking at $37^{\circ} \mathrm{C}, 200 \mathrm{rpm}$ in TSB. Then, different concentration of Biocide 1, Biocide 2, Biocide 3, benzalkonium chloride, hydrogen peroxide and mitomycin $\mathrm{C}$ were added into the broth culture respectively, and further incubated for $2 \mathrm{~h}$ at $37^{\circ} \mathrm{C}, 200 \mathrm{rpm}$. The concentration series of each biocide was determined according to MIC values of strain 8325-4 Ф13 (Table 3), which included MIC, 5X MIC, 10X MIC, 20X MIC, and 30X MIC. Supernatants were sterilized by $0.45 \mu \mathrm{m}$ pore diameter membrane filter. The phage induction levels were evaluated by PFU determination as previously described (Goerke et al., 2006b). Briefly, $100 \mu \mathrm{l}$ of each phage supernatant dilution was mixed $100 \mu \mathrm{l}$ indicator strain MW2c $\left(\mathrm{OD}_{600}=0.1\right)$ and incubated for $10 \mathrm{~min}$ at room temperature before mixing with top agar and pouring onto a TSA plated with $10 \mu \mathrm{M} \mathrm{CaCl}_{2}$, and further incubated overnight at $37^{\circ} \mathrm{C}$.

\section{Lysogenization Assay of $\Phi 13$ to LA-MRSA}

Strain 8325-4 Ф13-kana was used as the phage donor strain. Phage lysate were obtained by growing the strain to exponential phase $\left(\mathrm{OD}_{600}=0.8\right)$ at $37^{\circ} \mathrm{C}, 200 \mathrm{rpm}$, mixing with $1 \mu \mathrm{g} / \mathrm{ml}$ mitomycin $\mathrm{C}$ and further incubating for $4 \mathrm{~h}$ under the same condition. The culture was centrifuged at $4^{\circ} \mathrm{C}, 8,500 \mathrm{rpm}$ for $6 \mathrm{~min}$, and sterile filtered by $0.45 \mu \mathrm{m}$ pore diameter membrane filter before determining the titer. $\Phi 13$ lysogens were obtained by mixing phage $\Phi 13$-kana and LA-MRSA CC398 strains (61599 and 93616) at MOIs of $0.001,0.01,0.1,1,10,100$, and 1,000 and incubating the mixture at $30^{\circ} \mathrm{C}$ for $30 \mathrm{~min}$. Hundred microliter of the mixture was then spread on TSA plate containing 100 
TABLE 3 | MIC of strain 8325-4 for different chemical agents.

\begin{tabular}{lc}
\hline Chemical agent & MIC \\
\hline Mitomycin C (mg/L) & 0.125 \\
Biocide 1 $(\mathrm{V} / \mathrm{v})$ & $0.02 \%$ \\
Biocide 2 $(\mathrm{v} / \mathrm{v})$ & $0.02 \%$ \\
Biocide $3(\mathrm{~V} / \mathrm{v})$ & $5.00 \%$ \\
Hydrogen peroxide $(\mathrm{W} / \mathrm{W})$ & $0.03 \%$ \\
Benzalkonium chloride $(\mathrm{mg} / \mathrm{L})$ & 2.67 \\
Acetic acid $(\mathrm{V} / \mathrm{V})$ & $0.16 \%$ \\
Amine oxide $(\mathrm{V} / \mathrm{v})$ & $0.04 \%$ \\
Peracetic acid $(\mathrm{V} / \mathrm{v})$ & $0.01 \%$ \\
\hline
\end{tabular}

$\mu \mathrm{l} / \mathrm{ml}$ kanamycin, $10 \mu \mathrm{g} / \mathrm{ml}$ tetracycline and $5 \%$ of sheep blood (Kan-Tet plate), and incubated at $37^{\circ} \mathrm{C}$ overnight. Lysogens were selected as colonies able to grow on Kan-Tet plate. The plates were stored at $4^{\circ} \mathrm{C}$ overnight to detect $\beta$-hemolysin activity. Lysogens were verified by colony morphology and hemolysin activity (Supplementary Figure 6) as well as by PCR to detect $a h p \mathrm{~A} 3$ and sak genes. The lysogenization frequency was evaluated as the ratio of the $\Phi 13$ CC398 lysogen colony count $(\mathrm{CFU} / \mathrm{ml})$ on Kan-Tet plate ( $\Phi 13 \mathrm{CC} 398$ lysogen) to the total recipient colony count $(\mathrm{CFU} / \mathrm{ml})$ on TSA plate with $10 \mu \mathrm{g} / \mathrm{ml}$ tetracycline (Tet plate).

\section{PCR Analysis}

Bacterial DNA was released by suspending 2-3 colonies in $100 \mu \mathrm{l}$ Milli Q water and incubated at $95^{\circ} \mathrm{C}$ for $10 \mathrm{~min}$. For confirming the transfer of $\Phi 13$ to LA-MRSA CC398 strain, primer pair sakfor/sak-rev for the sak gene and primer pair kanR-for/kanR-rev for the aph gene were used. For checking if the hlb gene was intact, primer pair hlbPhi13attB-for/hlbPhi13attB-rev of $h l b$ gene was used. For primer sequences see Supplementary Table 1. PCR amplification was performed by mixing $12.5 \mu \mathrm{l}$ DreamTaq Green PCR Master Mix (2X) (Thermo Fisher Scientific), $10.5 \mu$ l Milli $\mathrm{Q}$ water, $1 \mu \mathrm{l}$ DNA template and $1 \mu \mathrm{l}(0.1 \mu \mathrm{M})$ each primer. For determining the attB core sequence mutation in strain 83254 and RN4220, the PCR products of hlb gene were purified by GeneJet PCR purfication kit (Thermo Fisher Scientific) and sequenced by Macrogen Inc.

\section{In Vitro Liquid Co-Cultivation Assay}

The liquid co-cultivation assay was carried out in TSB with donor strain 8325-4Ф13-kana resistant to kanamycin and recipient strain LA-MRSA 61599 resistant to tetracycline. In brief, both donor and recipient strains were grown to exponential phase (approximately $10^{8} \mathrm{cfu} / \mathrm{ml}$ ), and mixed with a ratio of $1: 1$. Different concentrations of hydrogen peroxide, Biocide 1 and mitomycin $\mathrm{C}$ were added to the culture, and then incubated at $37^{\circ} \mathrm{C}, 200 \mathrm{rpm}$ for $4 \mathrm{~h}$. Phage transfer was detected by plating serial dilutions on Kan-Tet plate and Tet plate followed by incubating at $37^{\circ} \mathrm{C}$ for $18 \mathrm{~h}$. The $\Phi 13 \mathrm{CC} 398$ lysogens were counted based on the colony morphology of $\Phi 13$ lysogens (Supplementary Figure 6) and also further confirmed the PCR program of sak and kan $\mathrm{R}$ genes. To confirm the lysogens were belonging to CC398 strain and avoid miscounting of donor strain 8325-4Ф13-kana, a spa-mecA multiplex PCR (Tang et al., 2017) was conducted to CC398 lysogens, which could differentiate CC398 lysogens to donor strain 8325-4Ф13-kana (Supplementary Figure 5). The transfer ratio of $\Phi 13$-kana was considered as the ratio of the $\Phi 13$ CC398 lysogen colony count on Kan- Tet plates $(\mathrm{CFU} / \mathrm{ml})$ to the recipient colony count on Tet plates $(\mathrm{CFU} / \mathrm{ml})$.

\section{INFLUENCE OF CHEMICAL AGENTS TO STRAINS AND PHAGE}

The influence of applied chemical regents to donor and recipient strains was separately evaluated by growth curve, which culture of both strains at exponential phase (approximately $10^{8} \mathrm{cfu} / \mathrm{ml}$ ) was treated with a series of concentrations of mitomycin C, hydrogen peroxide and Biocide1, and measured $\mathrm{OD}_{600}$ value every hour till $4 \mathrm{~h}$ at $37^{\circ} \mathrm{C}, 200 \mathrm{rpm}$. The influence of applied chemical to $\Phi 13$-kana was evaluated by treating the phage stock with a series of concentration of chemical agents and the plaque assay was conducted after $4 \mathrm{~h}$ at $37^{\circ} \mathrm{C}, 200 \mathrm{rpm}$, with the plaque assay mentioned above. The influence of applied chemical regents to the induction of $\Phi 13$ with the kanamycin resistant cassette was evaluated after $4 \mathrm{~h}$ of treatment by $\Phi 13$ induction assay mentioned above. In addition, the influence of chemical compounds present in Biocide 1 to the donor and recipient strains was evaluated individually by growth curve and $\Phi 13$ induction assays as described above in the presence of a series concentrations of peracetic acid, amine oxide and acetic acid.

\section{Characterization of LA-MRSA CC398 $\Phi 13$ Lysogens}

Stability of the prophages in CC398 $\$ 13$ lysogens was examined in $10 \Phi 13$ lysogens of strain 61599 and passaging them for 20 days. In brief, $5 \mu$ l overnight culture of each lysogen was diluted 1000 -fold in $5 \mathrm{ml} \mathrm{TSB}$ and incubated for $24 \mathrm{~h}$ at $37^{\circ} \mathrm{C}$, $200 \mathrm{rpm}$. After each passage, $100 \mu \mathrm{l}$ culture was spread on TSA plate containing $10 \mu \mathrm{g} / \mathrm{ml}$ tetracycline and incubated overnight at $37^{\circ} \mathrm{C}$. From this plate, 50 colonies were picked up and streaked on TSA plate containing both $100 \mu \mathrm{g} / \mathrm{ml}$ kanamycin and $10 \mu \mathrm{g} / \mathrm{ml}$ tetracycline and TSA plate containing only $10 \mu \mathrm{g} / \mathrm{ml}$ tetracycline, and then incubated overnight at $37^{\circ} \mathrm{C}$. The stability of each lysogen was determined by the ratio of colonies survived on TSA plate contain both kanamycin and tetracycline to the colonies survived on TSA plate containing only tetracycline. Further, lysogens with different $\Phi 13$ stability characteristics were sequenced by paired-end sequencing $(2 \times 251 \mathrm{bp})$ using Nextera XT DNA Library Preparation Kit (Illumina Inc.) on a MiSeq sequencer (Illumina Inc.). Contigs were de novo assembled using CLC-bio assembler (Qiagen).

\section{Lysogenization Assay of $\Phi 13$ attB Mutant}

Stains 8325-4Ф13attBmut and RN4220Ф13attBmut, and their wild type strains were individually mixed with the $\Phi 13$-kana phage stock at a MOI of 0.1 and were incubated at $37^{\circ} \mathrm{C}$ for 4 
hrs. After making serial dilutions, $100 \mu \mathrm{l}$ of each dilution series was spread on TSA plates with $5 \%$ sheep blood containing 100 $\mu \mathrm{l} / \mathrm{ml}$ kanamycin (Kan-plate) and TSA plate with $5 \%$ sheep blood (TSA plate), which were incubated at $37^{\circ} \mathrm{C}$ overnight. Lysogens were selected as colonies able to grow on Kan plate. The plates were stored at $4^{\circ} \mathrm{C}$ overnight to detect $\beta$-hemolysin activity. The lysogen frequency was determined as the ratio of colony count $(\mathrm{CFU} / \mathrm{ml})$ on Kan-plate to the total colony count $(\mathrm{CFU} / \mathrm{ml})$ on TSA plate. Further, PCR amplification of hlb gene to check if $h l b$ gene was interrupted, PCR amplification of $h l b$ gene including the $\Phi 13$ att B site was conducted for 16 colonies of lysogenized mutants.

\section{RESULTS}

\section{Induction of $\Phi \mathrm{Sa} 3$ by Biocides}

Staphylococcus aureus strain 8325 harbors a $\Phi$ Sa3 class of phage termed $\Phi 13$ (Iandolo et al., 2002). In this study, we applied strain $8325-4 \Phi 13$ (Goerke et al., 2006a), which is a derivative of the phage cured strain 8325-4 (Novick, 1967) lysogenized with $\Phi 13$ to evaluate if commercially available biocides can induce $\Phi S a 3$. We evaluated the susceptibility of strain 8325$4 \Phi 13$ to three commercially available biocides in addition to hydrogen peroxide, benzalkonium chloride as well as mitomycin C (Table 1) by MIC (Table 3). Further, we exposed the strain $8325-4 \Phi 13$ to these biocides and chemical reagents (Table 1) and monitored plaque formation on indicator strain MW2c. Strain MW2c is a derivative of strain MW2- $\Phi$ Sa3mw in which all phages have been cured (Wirtz et al., 2009). We found that excision of $\Phi 13$ was induced by mitomycin $\mathrm{C}(\leq 3.75 \mathrm{mg} / \mathrm{ml})$, by biocides containing hydrogen peroxide [Biocide $1 \quad(\leq 0.2 \%$ $\mathrm{v} / \mathrm{v})$ and $2(\leq 0.2 \% \mathrm{v} / \mathrm{v})]$ as well as by hydrogen peroxide $(\leq 0.9 \% \mathrm{w} / \mathrm{w})$ in a dose-dependent manner (Figures 1A-E). No induction of $\Phi 13$ was observed by benzalkonium chloride or Biocide 3 containing sodium hypochlorite as the active ingredient (Figures 1C,F) or in the absence of stimuli indicating that less than $10 \mathrm{pfu} / \mathrm{ml}$ is released.

\section{Transfer of $\Phi 13$ to LA-MRSA CC398}

To monitor integration of $\Phi 13$ into LA-MRSA CC398, a $\Phi 13$ phage stock was obtained by mitomycin $\mathrm{C}$ induction from strain 8325-4Ф13-kana, a derivative of $8325-4 \Phi 13$ where the 3 '-end of chps and $s c n$ in $\Phi 13$ has been replaced by the kanamycin resistance gene, aphA3. This phage stock was used to infect two tetracycline-resistant LA-MRSA CC398 strains 61599 and 93616 isolated from humans in Denmark (Table 2). Strain 61599 with spa type t034 (Larsen et al., 2015) was obtained from a pig farm worker and strain 93616 with spa type $\mathrm{t} 899$ (Larsen et al., 2016) was recovered from a mink farmer. Neither of the strains contained $\Phi$ Sa3 phage by sequence analysis (Larsen et al., 2015, 2016). After repeated attempts, only strain 61599 could be lysogenised with $\Phi 13$. At multiplicity of infection (MOI) of less than one, we observed colonies resistant to both kanamycin and tetracycline, indicating lysogenization of LA-MRSA CC398 by $\Phi 13$-kana (Supplementary Figure 1). To confirm that the resulting colonies were lysogens and not spontaneous antibiotic resistant mutants, we used PCR amplification of the aphA3 and sak genes of $\Phi 13$-kana (data not shown).

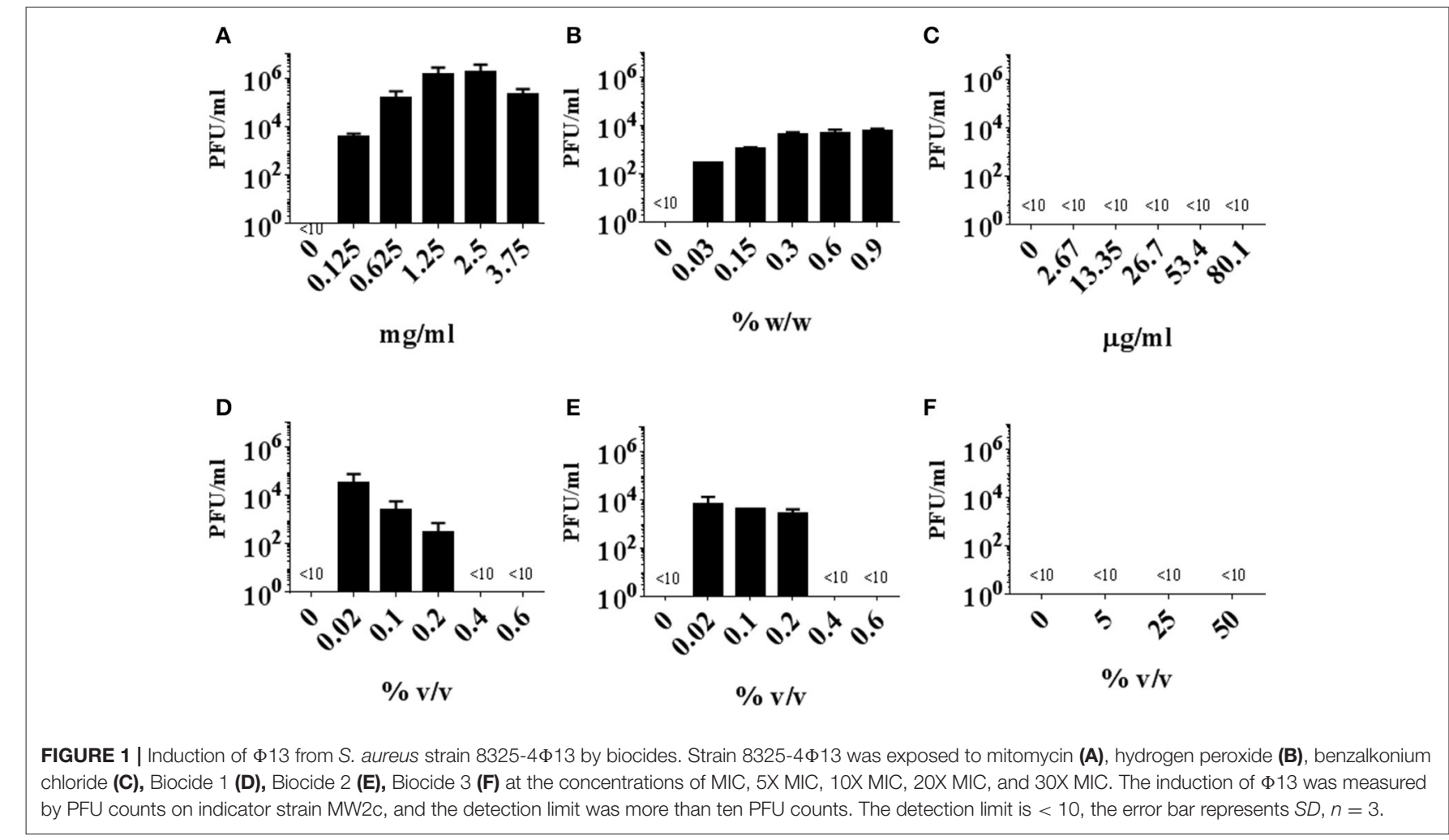


To examine if $\Phi 13$-kana could transfer directly from $S$. aureus 8325-4Ф13-kana (donor strain) to recipient LA-MRSA CC398 strain 61599 in the presence of biocides or mitomycin, we first assessed a series of concentrations of mitomycin C, hydrogen peroxide and Biocide 1 ranging from sub-lethal to lethal with respect to their influence on growth (Supplementary Figure 2) and the induction levels of $\Phi 13$-kana (Supplementary Figure 3 ). We also confirmed that these concentrations have minimum effect on $\Phi 13$-kana in plaque assays (Supplementary Figure 4). Further, we evaluated MIC of strain $8325-4 \Phi 13$ to acetic acid, amine oxide and peracetic acid (Table 1), which are present in Biocide 1 (Table 3), and exposed the strain to these chemicals to evaluate their effect on growth and $\Phi 13$ induction (Supplementary Figure 5). We found that, in addition to hydrogen peroxide (Supplementary Figure 3B), Ф13-kana can also be induced by peracetic acid, which is able to spontaneously decompose to hydrogen peroxide and acetic acid (Yuan et al., 1997; Supplementary Figure 6).

We co-cultured the donor strain 8325-4Ф13-kana with the recipient strain 61599, in the presence of sub-lethal to lethal concentrations of mitomycin $\mathrm{C}$, hydrogen peroxide, and Biocide 1. Colonies of strain 61599 lysogenized with $\Phi 13-$ kana were detected by plating on blood plates containing kanamycin and tetracycline. The transfer of $\Phi 13$-kana was confirmed by PCR for sak and aphA3 and the identity of the resulting colonies was confirmed by PCR amplification of spa and mecA (Supplementary Figure 7). We observed that Ф13-kana transferred from strain 8325-4Ф13-kana to 61599 with a transfer frequency between $10^{-5}$ and $10^{-6}$ in the presence of $0.002-0.1 \%(\mathrm{v} / \mathrm{v})$ Biocide 1 , which contains hydrogen peroxide as the active compound (Figure 2C). Exposure to mitomycin $\mathrm{C}$ and hydrogen peroxide also induced the transfer of $\Phi 13$-kana (Figures 2A,B). Surprisingly, in the absence of DNA damaging agents, we also observed a transfer frequency of $\Phi 13$-kana was around $2.3 \times 10^{-7}$ (Figure 2). These results show that sublethal to lethal concentrations of biocides containing hydrogen peroxide and mitomycin C promote transfer of $\Phi 13$ between human and livestock-adapted strains in vitro.

\section{Characterization of $\Phi 13$ in CC398 Lysogens}

Initially, we assessed hemolysin production of nine $\Phi 13$ lysogens (LY01-09) in LA-MRSA CC398 strain 61599 on blood agar plates and observed that all were $\beta$-hemolysin positive (Supplementary Figure 8) suggesting that the phage had not integrated in the hlb attachment site commonly preferred in human strains (Goerke et al., 2006b). Subsequently, we evaluated stability of the lysogens over a period of 20 days (corresponding to approximately 960 generations) by plating on tetracycline agar plates and recording the fraction of kanamycin-resistant colonies (Figure 3). Here we observed different stability patterns with $\Phi 13$-kana being completely stabile in six lysogens (LY01-06), and being partially stable in the rest of the lysogens with 44\% (LY08) and 29\% (LY09) of cells retaining the phage, respectively. In LY07, the percentage

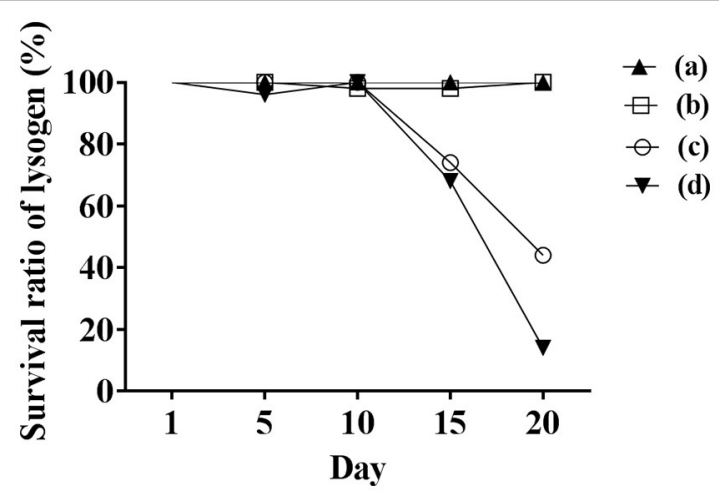

FIGURE 3 | Ф13 stability in LA-MRSA CC398 strain 61599. Nine lysogens were grown over a 20 period with 1000 fold dilution performed daily from the previous day overnight culture. The stability of the phage was monitored by plating on agar plates with tetracycline, and scoring the number that were also kanamycin resistant. (a) filled triangle represents LY01-LY06 of lysogens, which were fully stable with $\Phi 13$ prophages during the 20-day test; (b) opened square represents LYO7, which had sporadically lost $\Phi 13$ during 20 days; (c) open circle represent LY08 and (d) filled inverted triangle represents LY09, both lost $\Phi 13$ in the majority of the analyzed colonies after 20 days, respectively.
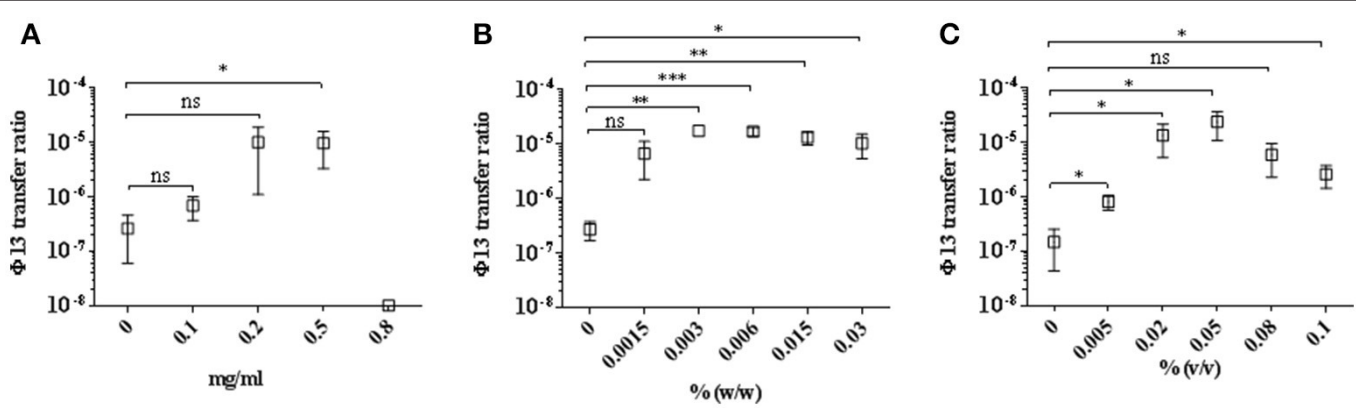

FIGURE 2 | Transfer of $\$ 13$ during co-cultivation of LA-MRSA CC398 with 8325-4Ф13-kana. Strains LA-MRSA CC398 and 8325-4Ф13-kana were co-cultivated and exposed for $4 \mathrm{~h}$ to different concentrations of $\mathbf{( A )}$ mitomycin $\mathbf{C}, \mathbf{B})$ hydrogen peroxide and $\mathbf{( C )}$ Biocide 1 . Open squares represent the $\Phi 13$ transfer ratio calculated as the number of colonies resistant to tetracycline and kanamycin relative to the number resistant to tetracycline. Error bars represent $\pm S D, n=3$. ${ }^{\star \star \star} P<0.001$,

${ }^{\star \star} P<0.01$ and ${ }^{\star} P<0.05$, NS, none significant by $t$-test analysis. 
of cells carrying the phage varied between 96 and 100\% during the experiment indicating sporadic loss. To examine the genetic basis for the different stability patterns we sequenced the genomes of lysogens and observed eight different $\Phi 13$ integration sites in strain 61599 (Table 4). In the six lysogens (LY01-LY06) where $\Phi 13$-kana was completely stable, the phage was integrated at six different locations in the chromosome of 61599. In five of the six lysogens (LY01-05), Ф13-kana was inserted in annotated genes, whereas in LY06 the phage was integrated in an unrelated intergenic region (Table 4). In LY07, where $\Phi 13$-kana stability varied the phage was integrated in a gene encoding a hypothetical protein located on plasmid JQ861959 that had integrated in the

TABLE 4 | Ф13 integration site in LA-MRSA CC398 strain 61599.

\begin{tabular}{|c|c|c|c|}
\hline Lysogen No. & $\Phi 13$ integration sites* & Function of gene integrated by $\Phi 13$ & att $B$ core sequence $\left(5^{\prime} \text { to } 3^{\prime}\right)^{\star \star *}$ \\
\hline LY01 & & Alanine racemase & GTIATCCAATCTGG \\
\hline LYO2 & & Nitrate reductase & GGGGACCTAACTGG \\
\hline LY03 & $R$ & Ornithine carbamoyltransferase & CCATICCATACTGG \\
\hline LYO4 & & $\begin{array}{l}\text { FADH(2)-oxidizing methylenetetrahydrofolate-tRNA- } \\
\text { (uracil(54)-C(5))-methyltransferase TrmFO) }\end{array}$ & GTGTATCCATETTGG \\
\hline LY05 & & Acyl esterase & IIIATCGTTCTGG \\
\hline LY06 & SAPIC & $\begin{array}{l}\text { SAPIG2164: aldehyde dehydrogenase family protein } \\
\text { SAPIG2165: HxIR family transcriptional regulator }\end{array}$ & IIATCCGTAATGC \\
\hline LYO7 & & Plamid JQ861959 integrated upstream of the mutB gene & TGTTCTITATCTGG \\
\hline LY08 & $R$ & Membrane protein & 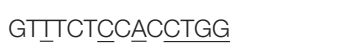 \\
\hline LYO9 & $R$ & Membrane protein & 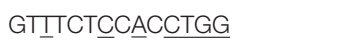 \\
\hline S. aureus COL & attB in hlb gene & $\Phi 13$ attachment site in hlb described by Coleman et al. (1991) & TGTATCCAAACTGG \\
\hline
\end{tabular}

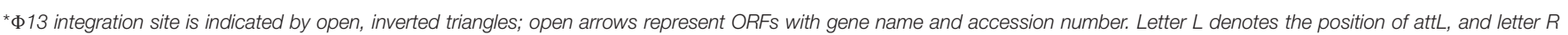
denotes the position of attR. ${ }^{\star \star}$ Letters with underline represent the nucleotides in attB that correspond to the core sequence of attB in hlb described by Coleman et al. (1991). 
chromosome, which may explain why recovery of the phage varied from plating to plating. In both LY08 and LY09 from which the phage was lost in the majority of cells after the 20 day period, $\Phi 13$-kana was integrated in yozB encoding a putative membrane protein, the function of which is unclear. These results strongly indicate that $\Phi 13$ integrates at alternative sites in LA-MRSA CC398 and that the overall stability of the integrated phage is influenced by its integration site in the chromosome.

By sequence analysis, we found that all integration sites in the nine lysogens were partially similar to the att $\mathrm{B}$ sequence for $\Phi 13$ in hlb gene originally described by Coleman et al. (1991) (Table 4). However, we were not able to observe other similarities between the integration sites or regions. By further comparing these integration sites in lysogens to the corresponding sequences in strain 61599 and strain 8325-4, we found that only the integration site in LY03 contained one nucleotide variation between the strain 61599 and strain 8325 -4, but this variation did not enhance resemblance to the att $\mathrm{B}$ in the $h l b$ gene (Supplementary Table 2). In addition, sequence analysis of the $h l b$ gene of strain 61599 revealed variation at two residues in the 14 nucleotide att $\mathrm{B}$ sequence when compared to at $\mathrm{B}$ in $h l b$ gene of the human derived strain S. aureus COL (Projan et al., 1989). Both nucleotide substitutions are silent leaving the $\beta$ hemolysin expression intact (Figure 4). This finding suggests that point mutations in $h l b$ of LA-MRSA may drive $\Phi 13$ to integrate elsewhere in the chromosome. To test this hypothesis, we compared the at $\mathrm{B}$ core sequence of $\Phi$ Sa3 from strain 61599 to the 69 of genome sequenced CC398 isolates from a previous study by Price et al. (2012). We observed that 65 out of 69 CC398 isolates from Price et al.'s study showed the same substitutions of the att $\mathrm{B}$ core sequence for $\Phi 13$ in the $h l b$ gene as we found in strain 61599, while four of CC398 isolates had three substitutions compared to the at $\mathrm{B}$ core sequence in $h l b$ described by Coleman et al. (1991; Figure 5).

To support our hypothesis that the mutation at attB in hlb of CC398 isolates influences integration of $\Phi$ Sa3, we mutated the $\Phi 13$ attB site of $h l b$ both in strain 8325-4 deviated from NCTC 8325 cured of $\Phi 11, \Phi 12$, and $\Phi 13$ (Novick, 1967), and in strain RN4220 derived from 8325-4 (Peng et al., 1988). After infecting both attB mutated strains with $\Phi 13$-kana at MOI of 0.1 , we observed a significant decrease in lysogenization of $\Phi 13$-kana in both at $\mathrm{B}$ mutant strains, when compared to the respective wild type control strains (Figure 6) and confirmed by
PCR amplification of hlb (Supplementary Figure 9) and aph3 (Supplementary Figure 10). These results demonstrate that point mutations of att B core sequence in $h l b$ of CC398 isolates strongly influence the integration of $\Phi S a 3$ into the $h l b$ gene, and the mutation favors $\Phi S a 3$ to integrate elsewhere in the bacterial genome and keeps the $h l b$ intact.

\section{DISCUSSION}

Mitomycin $\mathrm{C}$ and hydrogen peroxide are known to induce prophages in bacteria by causing DNA damage, which activates

\section{CC398 (65 isolates) TGTATCCGAATTGG CC398 (4 isolates) TATATCCGAATTGG 61599 TGTATCCGAATTGG 93616 TGTATCCGAATTGG X13404 TGTATCCAAACTGG}

FIGURE 5 | Variation of attB core sequence for $\Phi 13$ in hlb gene in $\Phi S a 3-n e g a t i v e$ CC398 isolates compared to the attB in hlb gene of $S$. aureus COL (accession no. X13404) described by Coleman et al. (1991). CC398 isolate information was obtained from the study of Price et al. (2012). The gray shaded letters represent the variations in the attB of CC398 isolates.

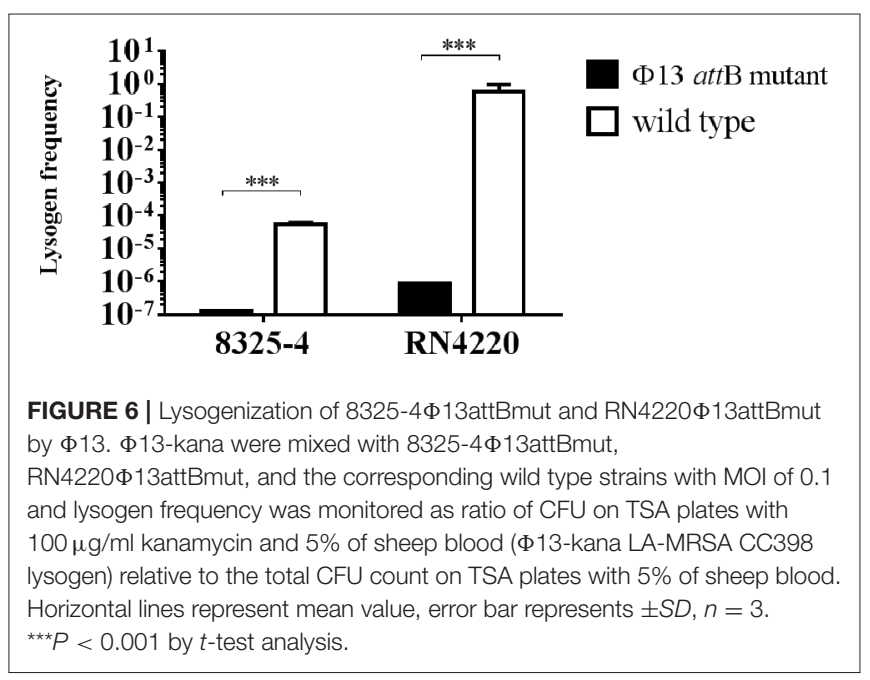


the SOS response and in turn cleaves the phage repressor (Frye et al., 2005; Goerke et al., 2006a; Loś et al., 2010; Nanda et al., 2015). Here, we show that commercial biocides containing hydrogen peroxide can induce phage $\Phi 13$, a phage belonging to Sa3 phage group that is known to encode human immune evasion genes and likely to be important for human colonization (Iandolo et al., 2002). Additionally, when co-culturing the human originating strain, 8325-4Ф13-kana with the livestock MRSA CC398 strain 61599 (spa type t034), the transfer frequency of $\Phi 13$ to strain 61599 was significantly increased in the presence of sublethal concentrations of hydrogen peroxide or commercial biocides containing hydrogen peroxide when compared to the transfer frequency without any treatment. Integration of $\Phi 13$ was also attempted in another LA-MRSA CC398 strain namely 93616 (spa type t899), but in this strain, we did not obtain lysogens. The inability of $\Phi 13$ to lysogenize strain 93616 could be caused by strain variations such as the restriction modification systems that restricts DNA transfer between staphylococcal lineages (Sadykov, 2016), or differences in wall teichoic acid glycopolymers that are the receptors of $\Phi 13$ and are highly strain-specific (Xia et al., 2010).

Hydrogen peroxide is a commonly applied bactericidal compound for disinfection in livestock production (Kjølholt et al., 2001). Our study indicates that this compound can act as an extrinsic factor contributing to the induction of $\Phi S \mathrm{Sa} 3$ by triggering excision and propagation of the prophage, and subsequent transfer from human to livestock-associated S. aureus strains. In contrast, neither sodium hypochlorite that is known to affect the bacterial cell wall (Maillard, 2002), nor benzalkonium chloride that is a membrane-active agent (SCHENIHR (Scientific Committee on Emerging and Newly Identified Health Risks), 2009), were able to induce $\Phi 13$. In the absence of external stimuli, no spontaneous induction of $\Phi 13$ was observed in concordance with a previous study (Goerke et al., 2006a). Interestingly, we did observe transfer of $\Phi 13$ from strain $8325-4 \Phi 13$-kana to strain 61599 when the two strains were co-cultured. The most likely reason for this is that $\Phi 13$ propagates on strain 61599 resulting in more phages that in turn increase the chance of phage integration in strain 61599.

$\Phi S a 3$ group is known as hlb-converting phages that integrate in the hlb-gene at the attB attachment site (5'-TGTATCC AAACTGG-3') recognized by the phage integrase (Coleman et al., 1991). A likely explanation for the atypical integration of $\Phi S a 3$ in strain 61599 is the two silent point mutations in the att $\mathrm{B}$ core sequence located within $h l b$. We speculate that these mutations in att $\mathrm{B}$ may be the reason that we did not observe phage integration in $h l b$ but rather at numerous other locations in the LA-MRSA CC398 strain 61599. These integration sites share homology to the att $\mathrm{B}$ core sequence for $\Phi 13$ (Coleman et al., 1991). In particularly seven of the eight integration site sequences contain a four nucleotides sequence $\left(5^{\prime}\right.$-CTGG- $\left.3^{\prime}\right)$ at the $3^{\prime}$-end, which is present in the $\Phi 13$ $a t t \mathrm{~B}$ core sequence in $h l b$ gene (5'-TGTATCCAAACTGG-3') (Coleman et al., 1991), but is not in the attB core sequence in $h l b$ from CC398 strains (5'-TGTATCCGAATTGG- $3^{\prime}$ and $5^{\prime}$-TATATCCGAATTGG-3'). We speculate that this sequence similarity is important for the integration of $\Phi$ Sa3 into CC398. It was previously reported that $\Phi 13$ can be integrated at different locations in S. aureus (Goerke et al., 2006b; Kraushaar et al., 2017), but the reason for the atypical integration of $\Phi$ Sa3 had not been studied before. Here, we exchanged the core sequence of $\Phi 13$ attB in $h l b$ from both strain 8325-4 and strain RN4220 to the attB core sequence from CC398 strain 61599. After infecting with $\Phi 13$, we observed a significant decrease in lysogenization frequency in the $\Phi 13$ attB mutants compared to cells carrying the intact $h l b$ gene. This result demonstrates that the mutations at the att $\mathrm{B}$ core sequence in $h l b$ gene of CC398 strain cause the low transfer frequency of $\Phi 13$ to CC398 strains and also drives the atypical integration of $\Phi 13$ in CC398 strains.

In conclusion, we show that in the presence of commercially available biocides containing hydrogen peroxide, $\Phi$ Sa3 is transferred from a human-associated S. aureus donor strain to a strain, belonging to the CC398 complex. Previous studies have shown that the CC398 ancestor was adapted to humans but jumped to animals by loss of prophage Sa3 during the close human-livestock activities (Price et al., 2012). Recently, it was shown that $\Phi S a 3$ may be re-introduced into livestock-associated CC398 strains in a single horizontal gene transfer event from human-associated S. aureus and that it can be maintained stably as a prophage in the CC398 lysogens (Larsen et al., 2016). Our study highlights the importance of environmental factors in transfer of $\Phi S a 3$ between $S$. aureus strains and that just a four nucleotides sequence may be enough to guide integration of the phage LA-MRSA strains. Future studies will be needed to determine if and how integration frequencies vary from strain to strain and to identify factors and conditions that may prevent $\Phi$ Sa3 transmission.

\section{AUTHOR CONTRIBUTIONS}

YT, JH, LN, CWo, and HI designed the study, YT and AH conducted the microbiological analysis, CWi and YT constructed strains, YT, JL, JH and $\mathrm{HI}$ analyzed the results. YT wrote the manuscript and YT, LN, AH, JH, CWi, PA, JL, CWo, and HI reviewed the manuscript.

\section{ACKNOWLEDGMENTS}

This work is supported by a Danish Research Council Sapere Aude grant to $\mathrm{JH}$, the Deutsche Forschungsgemeinschaft (GRK1708) and the PhD Scholarship from the Faculty of Health and Medical Sciences, University of Copenhagen. We would like to thank Elvira Chapka from Department of Microbiology and Infection Control, Statens Serum Institut for their technical assistance.

\section{SUPPLEMENTARY MATERIAL}

The Supplementary Material for this article can be found online at: https://www.frontiersin.org/articles/10.3389/fmicb. 2017.02418/full\#supplementary-material 


\section{REFERENCES}

Becker, K., Ballhausen, B., Kahl, B. C., and Köck, R. (2015). The clinical impact of livestock-associated methicillin-resistant Staphylococcus aureus of the clonal complex 398 for humans. Vet. Microbiol. 200, 33-38. doi: 10.1016/j.vetmic.2015.11.013

Bhat, M., Dumortier, C., Taylor, B. S., Miller, M., Vasquez, G., Yunen, J., et al. (2009). Staphylococcus aureus ST398, New York City and Dominican Republic. Emerging Infect. Dis. 15, 285-287. doi: 10.3201/eid1502.080609

Brückner, R. (2006). Gene replacement in Staphylococcus carnosus and Staphylococcus xylosus. FEMS Microbiol. Lett. 151, 1-8. doi: 10.1111/j.1574-6968.1997.tb10387.x

Clinical and Laboratory Standards Institute (CLSI). (2008). Preformance Standards for Antimicrobial Disk and Dilution Susceptibility Test for Bacteria Isolated from Animals; Approve Standard, $3 r d$ Edn. Wayne, PA: Clinical and Laboratory Standards Institute.

Coleman, D., Knights, J., Russell, R., Shanley, D., Birkbeck, T. H., Dougan, G., et al. (1991). Insertional inactivation of the Staphylococcus aureus $\beta$-toxin by bacteriophage $\phi 13$ occurs by site-and orientation-specific integration of the $\phi 13$ genome. Mol. Microbiol. 5, 933-939.

Coleman, D. C., Sullivan, D. J., Russell, R. J., Arbuthnott, J. P., Carey, B. F., and Pomeroy, H. M. (1989). Staphylococcus aureus bacteriophages mediating the simultaneous lysogenic conversion of beta-lysin, staphylokinase and enterotoxin A: molecular mechanism of triple conversion. J. Gen. Microbiol. 135, 1679-1697.

Cuny, C., Wieler, L. H., and Witte, W. (2015). Livestock-associated MRSA: the impact on humans. Antibiotics 4, 521-543. doi: 10.3390/antibiotics4040521

de Haas, C. J., Veldkamp, K. E., Peschel, A., Weerkamp, F., Van Wamel, W. J., Heezius, E. C., et al. (2004). Chemotaxis inhibitory protein of Staphylococcus aureus, a bacterial antiinflammatory agent. J. Exp. Med. 199, 687-695. doi: $10.1084 /$ jem.20031636

DeLeo, F. R., Otto, M., Kreiswirth, B. N., and Chambers, H. F. (2010). Communityassociated methicillin-resistant Staphylococcus aureus. Lancet 375, 1557-1568. doi: 10.1128/CMR.00081-09

Diene, S. M., Corvaglia, A. R., Francois, P., van der Mee-Marquet, N., and Regional Infection Control Group of the Centre, R. (2017). Prophages and adaptation of Staphylococcus aureus ST398 to the human clinic. BMC Genomics 18:133. doi: 10.1186/s12864-017-3516-x

Dulon, M., Haamann, F., Peters, C., Schablon, A., and Nienhaus, A. (2011). MRSA prevalence in European healthcare settings: a review. BMC Infect. Dis. 11:138. doi: 10.1186/1471-2334-11-138

Frye, J. G., Porwollik, S., Blackmer, F., Cheng, P., and McClelland, M. (2005). Host gene expression changes and DNA amplification during temperate phage induction. J. Bacteriol. 187, 1485-1492. doi: 10.1128/JB.187.4.1485-1492.2005

Goerke, C., Matias y Papenberg, S., Dasbach, S., Dietz, K., Ziebach, R., Kahl, B. C., et al. (2004). Increased frequency of genomic alterations in Staphylococcus aureus during chronic infection is in part due to phage mobilization. J. Infect. Dis. 189, 724-734. doi: 10.1086/381502

Goerke, C., Pantucek, R., Holtfreter, S., Schulte, B., Zink, M., Grumann, D., et al. (2009). Diversity of prophages in dominant Staphylococcus aureus clonal lineages. J. Bacteriol. 191, 3462-3468. doi: 10.1128/JB.01804-08

Goerke, C., Koller, J., and Wolz, C. (2006a). Ciprofloxacin and trimethoprim cause phage induction and virulence modulation in Staphylococcus aureus. Antimicrob. Agents Chemother. 50, 171-177. doi: 10.1128/AAC.50.1.171-177.2006

Goerke, C., Wirtz, C., Fluckiger, U., and Wolz, C. (2006b). Extensive phage dynamics in Staphylococcus aureus contributes to adaptation to the human host during infection. Mol. Microbiol. 61, 1673-1685. doi: 10.1111/j.1365-2958.2006.05354.x

Guérout-Fleury, A. M., Shazand, K., Frandsen, N., and Stragier, P. (1995). Antibiotic-resistance cassettes for Bacillus subtilis. Gene 167, 335-336. doi: 10.1016/0378-1119(95)00652-4

Iandolo, J. J., Worrell, V., Groicher, K. H., Qian, Y., Tian, R., Kenton, S., et al. (2002). Comparative analysis of the genomes of the temperate bacteriophages phi 11, phi 12 and phi 13 of Staphylococcus aureus 8325. Gene 289, 109-118. doi: 10.1016/S0378-1119(02)00481-X

Jung, P., Abdelbary, M. M. H., Kraushaar, B., Fetsch, A., Geisel, J., Herrmann, M., et al. (2016). Impact of bacteriophage Saint3 carriage on the immune evasion capacity and hemolytic potential of Staphylococcus aureus CC398. Vet. Microbiol. 200, 46-51. doi: 10.1016/j.vetmic.2016.02.015

Kjølholt, J., Nielsen, P. J., and Samsøe-Petersen, L. (2001). Inventory of Biocides Used in Denmark. Environmental Project No. 585. Copenhagen: Miljøstyrelsen.

Köck, R., Siam, K., Al-Malat, S., Christmann, J., Schaumburg, F., Becker, K., et al. (2011). Characteristics of hospital patients colonized with livestockassociated meticillin-resistant Staphylococcus aureus (MRSA) CC398 versus other MRSA clones. J. Hosp. Infect. 79, 292-296. doi: 10.1016/j.jhin.2011. 08.011

Kraushaar, B., Hammerl, J. A., Kienöl, M., Heinig, M. L., Sperling, N., Dinh Thanh, M., et al. (2017). Acquisition of virulence factors in livestock-associated MRSA: lysogenic conversion of CC398 strains by virulence gene-containing phages. Sci. Rep. 7:2004. doi: 10.1038/s41598-017-02175-4

Kreiswirth, B. N., Löfdahl, S., Betley, M. J., O’Reilly, M., Schlievert, P. M., Bergdoll, M. S., et al. (1983). The toxic shock syndrome exotoxin structural gene is not detectably transmitted by a prophage. Nature 305, 709-712.

Larsen, J., Petersen, A., Sørum, M., Stegger, M., van Alphen, L., Valentiner-Branth, P., et al. (2015). Meticillin-resistant Staphylococcus aureus CC398 is an increasing cause of disease in people with no livestock contact in Denmark, 1999 to 2011. Euro. Surveill. 20, 5-13. doi: 10.2807/1560-7917.ES.2015.20.37.30021

Larsen, J., Stegger, M., Andersen, P. S., Petersen, A., Larsen, A. R., Westh, H., et al. (2016). Evidence for human adaptation and foodborne transmission of livestock-associated methicillin-resistant Staphylococcus aureus. Clin. Infect. Dis. 63, 1349-1352. doi: 10.1093/cid/ciw532

Loś, J. M., Loś, M., Wegrzyn, A., and Wegrzyn, G. (2010). Hydrogen peroxidemediated induction of the Shiga toxin-converting lambdoid prophage ST28624 in Escherichia coli O157:H7. FEMS Immunol. Med. Microbiol. 58, 322-329. doi: 10.1111/j.1574-695X.2009.00644.x

Maillard, J. Y. (2002). Bacterial target sites for biocide action. J. Appl. Microbiol. 16S-27S. doi: 10.1046/j.1365-2672.92.5s1.3.x

McCarthy, A. J., and Lindsay, J. A. (2010). Genetic variation in Staphylococcus aureus surface and immune evasion genes is lineage associated: implications for vaccine design and host-pathogen interactions. BMC Microbiol. 10:173. doi: 10.1186/1471-2180-10-173

Monk, I. R., Shah, I. M., Xu, M., Tan, M. W., and Foster, T. J. (2012). Transforming the untransformable: application of direct transformation to manipulate genetically Staphylococcus aureus and Staphylococcus epidermidis. MBio 3:e0277-11. doi: 10.1128/mBio.00277-11

Nanda, A. M., Thormann, K., and Frunzke, J. (2015). Impact of spontaneous prophage induction on the fitness of bacterial populations and host-microbe interactions. J. Bacteriol. 197, 410-419. doi: 10.1128/JB.02230-14

Novick, R. (1967). Properties of a cryptic high-frequency transducing phage in Staphylococcus aureus. Virology 33, 155-166. doi: 10.1016/0042-6822(67)90105-5

Peng, H. L., Novick, R. P., Kreiswirth, B., Kornblum, J., and Schlievert, P. (1988). Cloning, characterization, and sequencing of an accessory gene regulator (agr) in Staphylococcus aureus. J. Bacteriol. 170, 4365-4372. doi: $10.1128 /$ jb.170.9.4365-4372.1988

Pérez-Moreno, M. O., Centelles-Serrano, M. J., Nogales-López, J., DomenechSpanedda, M. F., Lozano, C., and Torres, C. (2016). Unusual presence of the immune evasion gene cluster in livestock-associated MRSA of lineage CC398 causing peridural and psoas abscesses in a poultry farmer. Enferm. Infecc. Microbiol. Clin. doi: 10.1016/j.eimc.2016.07.008. [Epub ahead of print].

Price, L. B., Stegger, M., Hasman, H., Aziz, M., Larsen, J., Andersen, P. S., et al. (2012). Staphylococcus aureus CC398: host adaptation and emergence of methicillin resistance in livestock. MBio 3:e00305-11. doi: 10.1128/mBio.00305-11

Projan, S. J., Kornblum, J., Kreiswirth, B., Moghazeh, S. L., Eisner, W., and Novick, R. P. (1989). Nucleotide sequence: the beta-hemolysin gene of Staphylococcus aureus. Nucleic Acids Res. 17:3305. doi: 10.1093/nar/17.8.3305

Quinn, P. J., and Markey, B. K. (2001). "Disinfection and disease prevention in veterinary medicine," in Disinfection, Sterilization and Preservation, 5th Edn. ed S. Block (Philadelphia, PA: Lea \& Febiger), 1069-1103.

Rooijakkers, S. H., Ruyken, M., Roos, A., Daha, M. R., Presanis, J. S., Sim, R. B., et al. (2005). Immune evasion by a staphylococcal complement inhibitor that acts on C3 convertases. Nat. Immunol. 6, 920-927. doi: 10.1038/ ni1235 
Russell, A. D. (2003). Similarities and differences in the responses of microorganisms to biocides. J. Antimicrob. Chemother. 52, 750-763. doi: $10.1093 / \mathrm{jac} / \mathrm{dkg} 422$

Sadykov, M. R. (2016). "Restriction-modification systems as a barrier for genetic manipulation of Staphylococcus aureus," in The Genetic Manipulation of Staphylococci: Methods and Protocols, ed J. L. Bose (New York, NY: Springer New York), 9-23.

SCHENIHR (Scientific Committee on Emerging and Newly Identified Health Risks) (2009). Assesssment of the Antibiotic Resistance Effects of Biocides. Brussels: SCHENIHR.

Schijffelen, M. J., Boel, C. H, van Strijp, J. A., and Fluit, A. C. (2010). Whole genome analysis of a livestock-associated methicillin-resistant Staphylococcus aureus ST398 isolate from a case of human endocarditis. BMC Genomics 11:376. doi: 10.1186/1471-2164-11-376

Smith, T. C. (2015). Livestock-associated Staphylococcus aureus: the United States experience. PLoS Pathog. 11:e1004564. doi: 10.1371/journal.ppat.10 04564

Smith, T. C., and Pearson, N. (2011). The emergence of Staphylococcus aureus ST398. Vector Borne Zoonotic Dis. 11, 327-339. doi: 10.1089/vbz.2010.0072

Tang, Y., Larsen, J., Kjeldgaard, J., Andersen, P. S., Skov, R., and Ingmer, H. (2017). Methicillin-resistant and -susceptible Staphylococcus aureus from retail meat in Denmark. Int. J. Food Microbiol. 249, 72-76. doi: 10.1016/j.ijfoodmicro.2017.03.001

van Cleef, B. A., Monnet, D. L., Voss, A., Krziwanek, K., Allerberger, F., Struelens, M., et al. (2011). Livestock-associated methicillin-resistant Staphylococcus aureus in humans, Europe. Emerging Infect. Dis. 17, 502-505. doi: $10.3201 /$ eid1703.101036

van der Mee-Marquet, N. L., Corvaglia, A., Haenni, M., Bertrand, X., Franck, J. B., Kluytmans, J., et al. (2014). Emergence of a novel subpopulation of CC398 Staphylococcus aureus infecting animals is a serious hazard for humans. Front. Microbiol. 5:652. doi: 10.3389/fmicb.2014.00652

van Loo, I., Huijsdens, X., Tiemersma, E., de Neeling, A., van de SandeBruinsma, N., Beaujean, D., et al. (2007). Emergence of methicillin-resistant Staphylococcus aureus of animal origin in humans. Emerging Infect. Dis. 13, 1834-1839. doi: 10.3201/eid1312.070384 van Wamel, W. J., Rooijakkers, S. H., Ruyken, M., van Kessel, K. P., and van Strijp, J. A. (2006). The innate immune modulators staphylococcal complement inhibitor and chemotaxis inhibitory protein of Staphylococcus aureus are located on beta-hemolysin-converting bacteriophages. J. Bacteriol. 188, 1310-1315. doi: 10.1128/JB.188.4.1310-1315.2006

Welinder-Olsson, C., Floren-Johansson, K., Larsson, L., Oberg, S., Karlsson, L., and Ahren, C. (2008). Infection with Panton-Valentine leukocidin-positive methicillin-resistant Staphylococcus aureus t034. Emerging Infect. Dis. 14, 1271-1272. doi: 10.3201/eid1408.071427

Wirtz, C., Witte, W., Wolz, C., and Goerke, C. (2009). Transcription of the phageencoded Panton-Valentine leukocidin of Staphylococcus aureus is dependent on the phage life-cycle and on the host background. Microbiology 155(Pt 11), 3491-3499. doi: 10.1099/mic.0.032466-0

Wulf, M. W., Markestein, A., van der Linden, F. T., Voss, A., Klaassen, C., and Verduin, C. M. (2008). First outbreak of methicillin-resistant Staphylococcus aureus ST398 in a Dutch hospital, June 2007. Euro Surveill. 13:8051. doi: 10.2807/ese.13.09.08051

Xia, G., Maier, L., Sanchez-Carballo, P., Li, M., Otto, M., Holst, O., et al. (2010). Glycosylation of wall teichoic acid in Staphylococcus aureus by TarM. J. Biol. Chem. 285, 13405-13415. doi: 10.1074/jbc.M109.096172

Yuan, Z., Ni, Y., and Van Heiningen, A. R. P. (1997). Kinetics of peracetic acid decomposition: part I: spontaneous decomposition at typical pulp bleaching conditions. Can. J. Chem. Eng. 75, 37-41. doi: 10.1002/cjce.5450750108

Conflict of Interest Statement: The authors declare that the research was conducted in the absence of any commercial or financial relationships that could be construed as a potential conflict of interest.

Copyright (C) 2017 Tang, Nielsen, Hvitved, Haaber, Wirtz, Andersen, Larsen, Wolz and Ingmer. This is an open-access article distributed under the terms of the Creative Commons Attribution License (CC BY). The use, distribution or reproduction in other forums is permitted, provided the original author(s) or licensor are credited and that the original publication in this journal is cited, in accordance with accepted academic practice. No use, distribution or reproduction is permitted which does not comply with these terms. 